\title{
Designing a Proposed program on healthy behavior in practicing sport for primary stage pupils as a companion curriculum
}

\section{*Dr/ Khaled Mohamed Abdelgaber Mohamed Elkhateeb Introduction and Research Problem:}

Physical Education plays

an important role in society structure, as it takes care of the individual's health, entity and gains him kinetics and fitness skills resulted in various attractive and interesting ways to health methods in interacting and refine his behavior and improving trends and desires .(9:9)

It was found that sports activities lead to satisfy of desires, trends and bring joy and pleasure and thus helps to psychological balance, emotional stability and reduces the internal tension. This in turn leads to improve mental health, sports activities also resulted in the development of fitness and increase the effectiveness of body organs thus muscles, nerves and physical organs functioned efficiently when it is fit for exercise its function. When these organs do not exercise physical activity they largely lose their ability to work. $(6: 25)$

Practicing of sport activities improve information and knowledge related to the nature of the activity exercised by the individual, which in turn increase the level of individual mental health, in addition sport activities exercise resulted in a good behavioral patterns such as obedience and adherence as well as the development of social relations between individuals and groups. (22: 50)

Schools are one of the most influential in Community and Social institutions, they are responsible for the large group of community's members as they cooperate with family to child- upbringing. Due to the spread of illiteracy among parents and the low health cultural level, sometimes family alone cannot do this. The primary school is one of the most important grades of

Lecturer curricula and teaching Physical Education Department, Faculty of Physical Education in New Valley, Assiut University

Assiut Journal For Sport Science Arts 
education affecting the student's personality because of the psychological, health. Physiological and physical changes impact on his behavior, trends, and which affects an individual in the following stages life. $(21: 246)$

The primary school of the most important stages of education affecting the student's personality to what is happening out of the psychological and health and physiological changes and affect the physical behavior and trends, which affect the individual in the following stages of his life .(15:23)

On the other hand, the primary school students see their teachers, especially physical education teacher as the role models and ideals, and it becomes easy influenced by trends and behaviors, and whenever the teacher was in good health and practicing healthy habits and has a healthy trends intact whenever he had the greatest impact on the development trends and positive health behavior. (5: 152)

Physical Education is a mean to form a good health habits, because physical education is a fundamental tool to improve students healthy behavior, as its various activities are of the favorite, lovely and attractive subjects for students, through them they acquired the good behavior and health habits.(10:6)

From the foregoing and through researchers reading and viewing on some Arab and foreign references and resort to some primary schools. The researcher has noticed that the physical education curriculum are confined to the practical side, teaching only without attention to the necessary health habits and behavior. Students also have serious shortcomings in health education and health habits to be followed in general and at sporting activities in particular. On the other hand, education is one of the most important stages of education, which significantly contribute to the building of personal habits and behavior of the individual. Physical Education is one of the major areas desirable and acceptable to the students that can contribute to modify the behavior of pupils. Thus the researcher needs to to design a proposed program on healthy behavior in practicing sport for 
primary stage Pupils as a companion curriculum.

The Objective of the Research:

This study Research aims to design a proposed program on healthy behavior in practicing sport for primary stage pupils as a companion curriculum.

\section{Research Questions:}

1. What are the objectives of the proposed program on health behavior in practicing sport for primary stage pupils as a companion curriculum?

2. What is the content of the proposed program on health behavior in practicing sport for primary stage pupils as a companion curriculum?

3. What methods and ways of teaching and learning of the proposed program on health behavior in practicing sport for primary stage pupils as a companion curriculum?

4. What Means and device of the proposed program on health behavior in practicing sport for primary stage pupils as a companion curriculum?

5. What time frame of the proposed program on health behavior in practicing sport for primary stage pupils as a companion curriculum?
6. What Evaluation methods of the proposed program on health behavior in practicing sport for primary stage pupils as a companion curriculum?

\section{Previous Studies}

1. A Study by Nasrin Nadia Abdalgid (2011) (19) titled "an instruction manual in Health Education for Teachers of Physical Education phase primary education", the study aimed to build a guide health education to physical education teachers in primary education researcher used the descriptive method (survey) studies and reached the study sample (10) expert, (30) is directed, (230) teachers, (26) doctor, (160) health visitors, the researcher used the questionnaire and the personal interview to collect the data of the study, and the study resulted in the following findings build a guide health education to physical education teachers stage of primary education . The study recommended the need to disseminate this toolkit for the benefit of physical education teachers in primary education to identify the types of malformations skeleton kinetic and injuries that occur to students during the sports 
portion of education at this stage and how to treat them and work them first aid.

2. A Study by Amani Ahmed Mohammed (2010)(3), titled: "The Impact of health education program to raise the level of health for pupils of the first stage of primary education" the study aims at designing health education program, and but measure of health and culture, the sample included 130 first stage schoolgirl of primary education. The researcher used the questionnaire and personal interview for data collection. the results indicate the importance of designing health education program and put scale for health education, and recommended the need for program application on the first grade students of primary education

3. A Study by Amera Khatab Ahmed (2008) (4), titled:" the impact of Computerized health education program to improve the health behavior of children of (s.o.s) Foundation for orphans , in Gharbia" The study aimed to identify the impact of Computerized health education program to improve the health behavior of children of (s.o.s) foundation for orphans- Gharbia, the researcher used descriptive and experimental approach. The sample consists of 169 children, Questionnaire and personal interview for data collection, the results showed that there are statistically significant differences in favor of the experimental group after the application of the program. 4.A Study by Gehan AbdElaziz Jamal (2005)(8) titled: "Effect of education program (healthy - athlete) to reduce the rate of injuries to students of sports experimental schools Alexandria, The study aimed to know the impact of the program to reduce the rate of injuries to students of sports experimental schools, the researcher used the descriptive and experimental method, the sample included 154 students from high school .The results showed that the program had an effective impact in raising the level of sports health culture and reduce the injuries rate among experimental group subjects.

5. A Study by Mahmoud Ramadan Hassan (2005) (13) titled: "Designing evaluate tag to sport school health for primary school students," the study aimed to designing 
evaluation tag to sport school health for primary school students, according to the facilities of the schools in the Egyptian environment, The researcher used the descriptive method, the sample included 553 students from the primary level, the researcher used the questionnaire form for data collection, and the most important results are to put standard levels to test physical fitness of students in rural and urban in Kefir El-Sheikh.

\section{A Study by Mohammed} Sharaf Ahmed (2004)(18) titled: "health trends and their relationship to health behavior in the age (9-12 years) ", the study aimed to identify health trends and behavior of the students aged (9-12 years). The researcher used the descriptive approach, the sample included 960 students from the third, fourth and fifth class, used the questionnaire to collect data, and the results showed the statistically significant relationship between the student's health trends and health behavior at private and public school.

7. A Study by Gotay CC1, Shimizu H, Muraoka M, Ishihara Y, Tsuboi $\mathrm{K}$, Ogawa H (2004)(9) titled "Comparison of the health trends of health and behavior of the Americans of Japanese and European Ancestry. The study aimed to identify health trends and health behavior of the Americans of Japanese and European Ancestry, the researcher used the descriptive studies Survey) reached the study sample (420) and use The questionnaire as a tool for data collection, and study resulted in the following findings that the Japanese have put priority to the health of the health and behavior of the US. 8.A Study by Shingo N, Takeo M (2002) (23) titled: "the education experiments of school health promotion for the youth in Japan analysis of the (sport test) over the past 34 years". The study investigate the effect of physical education in Japan to improve the level of health among young people, the researcher used the survey studies, the sample included the six classes of the primary school, the results showed that media, especially television have a significant impact on improving school health for young people.

Study plan and procedures: Study methodology : 
The researcher used the descriptive approach (surveys) .The sample of the study is (19) expert in faculties of physical education specialists in the field of curriculum and teaching methods of sports and health, (72) a teacher and directed physical education in primary education in Assiut been chosen randomly.

Data collection tools:

- The researcher used the personal interview with researcher with have to experience and opinion in the field of curriculum and teaching methods of sports, health, teachers and supervisors of Physical Education,

- The researcher has analyzed some of the references and scientific studies related to the study, which was conducted in this area and to identify the steps to be followed to achieve the aims of the study.

- The researcher designed alquestionnaire proposed program.

Questionnaire proposed for the program:

The proposal aims to design a program to give health behavior at sports practice among primary school pupils.
Steps designed questionnaire proposed for the program:

By looking at some of the previous studies, periodicals and scientific references related to the subject area of the study, which was conducted in this area in order to identify the key points for the preparation of the questionnaire. The researcher agroup of the main axes to form questionnaire and were introduced by a group of experts and their number is (19), expert of specialists in the field of curriculum and teaching methods, health and sports. for an opinion on the appropriateness of this axes key interlocutor to form questionnaire attachment (1) shows that.

\section{The form initial proposal for the program:}

The researcher made preparation for the proposed program through personal interviews with teachers and education supervisors of sports, as well as through surveys for some references and studies specialized in the design and construction of all the programs that helped in the design of the proposed program of scientific research. The researcher presented with 
a group of experts and their number (19) of specialists in the field of curriculum and teaching methods of sports and health. express an opinion on the appropriateness of the terms of the axes of the questionnaire in terms of the aims of the program, as well as content It proposed that the program can achieve these aims, and the most suitable methods and ways of teaching and learning, which can be used in the proposed program content, and determine the appropriate means and assistive devices that are used in education and implementation of content, and methods appropriate calendar and asked the gentlemen experts make the necessary adjustments by deletion or merger or the addition of any term of the questionnaire phrases. Attachment (2) describes the axes of the program and phrases that have been agreed upon. The questionnaire was approved phrases, which got more than the proportion (70\% (of experts agreement has been deleted (2) statement that received less than the proportion $(70 \%$ (of experts agreement.
The final form of the questionnaire:

After reviewing the expert opinion and analysis was performed amendments proposed by the gentlemen of experts, as well as making the necessary scientific transactions, the researcher suggested questionnaire finalized (63) gateway

Scientific transactions of the questionnaire:

\section{First: Honesty:}

Use the sincerity of arbitrators display the questionnaire on a group of experts and their number (19) of specialists in the field of curriculum and teaching methods, health and sports in order to express an opinion on the suitability of the questionnaire as it was placed in terms of both (goals, content, methods and ways of teaching and learning aids, devices, frame time, evaluation methods) the proposed program. The litmus test has been made to be approved on the ferry from the $70 \%$ ratio Based on this questionnaire has been approved phrases, which got 70 percent or more of the experts agreement.

Second, the stability of the questionnaire: 
The stability of the questionnaire account through Cronbach's coefficient and retail midterm equation Alpha

Table (1) shows that.

Table (1)

Retail midterm firming and Alpha Cronbach's coefficient of the designing a Proposed program on healthy behavior in practicing sport for primary stage pupils as a companion curriculum. $(\mathbf{N}=19)$

\begin{tabular}{|c|c|c|c|c|}
\hline \multirow[b]{2}{*}{ Axes } & \multirow{2}{*}{$\begin{array}{l}\text { The } \\
\text { correlation } \\
\text { coefficient }\end{array}$} & \multicolumn{2}{|c|}{ Correct length scale } & \multirow{2}{*}{$\begin{array}{c}\text { Alpha } \\
\text { Cronbach's } \\
\text { coefficient }\end{array}$} \\
\hline & & $\begin{array}{c}\text { Spearman } \\
\text { - Brown }\end{array}$ & Gettman & \\
\hline Program aims & 0.775 & 0.881 & 0.882 & 0.703 \\
\hline Program content & 0.812 & 0.896 & 0.897 & 0.771 \\
\hline $\begin{array}{l}\text { Methods and ways } \\
\text { of teaching and } \\
\text { learning }\end{array}$ & 0.754 & 0.860 & 0.862 & 0.761 \\
\hline Means and & 0.842 & 0.914 & 0.915 & 0.705 \\
\hline Time frame & 0.894 & 0.944 & 0.944 & 0.679 \\
\hline Evaluation & 0.845 & 0.946 & 0.946 & 0.741 \\
\hline total summation & 0.875 & 0.965 & 0.964 & 0.789 \\
\hline \multicolumn{2}{|c|}{$\begin{array}{l}\text { It is clear from Table (1) the } \\
\text { following: } \\
\text { Through mid-term stability } \\
\text { of retail transactions, we find that } \\
\text { the stability of Spearman - Brown } \\
\text { coefficients ranged between } \\
(0860: 0965) \text {, and using the } \\
\text { equation Gettman values ranged } \\
\text { between (0862: 0964), a function } \\
\text { of the values at the level of } \\
\text { significance (0.01), as Alpha } \\
\text { Cronbach's coefficient } \\
\text { coefficients ranged between (0700 } \\
: 0789) \text {, all of which are values of } \\
\text { a function at the level of } \\
\text { significance }(0.01) \text {, and through } \\
\text { the values of stability it is clear }\end{array}$} & \multicolumn{3}{|c|}{$\begin{array}{l}\text { that the questionnaire is } \\
\text { characterized by a high degree of } \\
\text { stability, giving a strong } \\
\text { indication of the possibility of a } \\
\text { reliable measurement of the } \\
\text { proposed program to give health } \\
\text { behavior at sports practice for } \\
\text { primary school students. } \\
\text { The application of the } \\
\text { questionnaire: } \\
\text { The researcher applying } \\
\text { the questionnaire to all the } \\
\text { sample under study and adult } \\
\text { stature (72) male and directed } \\
\text { physical education in primary } \\
\text { education in Assiut, with the }\end{array}$} \\
\hline
\end{tabular}


aim of identifying the suitability of the proposed program is to give health behavior in Sports practice for primary school students.

\section{The questionnaire forms are correct:}

After the completion of the application on the study sample, the researcher corrected the forms through the balance of Tri my estimation, has been corrected forms are as follows: an appropriate three (3) degrees,

\section{Suitable to some extent (2)} two degrees

Inappropriate (1) by one degree.

Statistical processors used: After data collection and tabulation were processed statistically and calculate the results of the study, the researcher used the following statistical methods: the percentage, the correlation coefficient for Spearman Brown, Getman equation, the Alpha Cronbach's coefficient , Libra estimated, the estimated degree. It has embraced a researcher at the level of significance (0.01) as the researcher used Spss program to calculate some statistical transactions.
Showing results of the study and interpretation:

Present the results of the study question:

What the proposed program to give health behavior at sports practice among primary school pupils?

First, the Aims of the proposed program

It is seen from the Table (2) as follows: The study sample that the proposed aims of the program are suitable where the proportion ranged from (78.2\%: 100\%). Based on that has been approved for all proposed aims of the program for getting on top of the $70 \%$ of the sample agreement ratio.

These results are obtaining some of the aims ratio (100\%), which refers to the importance of the aims, appropriateness and adequacy to provide students with information and knowledge to give students proper health behavior and modify their attitudes that are the foundation of all behaviors and represent a basic rule that that underlies any subsequent know, by identifying the proposed aims of the program are the educational process guide, determining targets accurately represents the light that goes by the organizers of 
the building program and determine the educational process and landmarks through which to determine the appropriate content, and the aims set for the program stems from the proposed community.

The second axis: the content of the program:

Seen from the Table (3) as follows: The study sample that the proposed program content is suitable where the proportion ranged from (85.2\%: 100\%) Based on that were approved all the proposed content of the program for getting on top of the $70 \%$ of the agreement ratio the sample. These results are obtaining some of the activities on the ratio $(100 \%)$, which refers to the importance of this activity, appropriateness and adequacy in achieving the objectives of the program to give proper health behavior of pupils, and the process of identification and selection of program content of the basic processes that are offset some difficulties as the extent of learning and achieving aims depend on the proper choice of content, organization, content is the foundation in the educational process because it depends on the educational material that will not let the pupils in order to reach an appropriate level, so it took into account the researcher to knowledge, information and skills provided for pupils to be based on actual fact and be of a practical nature applied to achieve the desired aims of the program so as to ensure effective implementation of the program.

The Third axis : the methods of teaching and learning

Seen from the Table (4) as follows:

The sample of the study that the methods and ways of teaching and learning of the proposed program is appropriate where the proportion ranged from (94.4\%: 100\%) Based on that has been approved for all methods and ways of teaching and learning of the proposed program for getting on top of the $70 \%$ of the sample agreement ratio.

The researcher obtains some of the techniques and methods of teaching and learning at the rate of $(100 \%)$, which refers to the importance of the methods and ways of teaching and learning of the proposed program and the 
appropriateness and adequacy in achieving the aims.

The researcher sees the need to diversify the teacher in the ways and means, which followed with his disciples depending on the nature of the activity and aims of teaching and the experiences of former students and appropriate extent of activity to the level of student growth, and vary these methods and ways of activity to another and pupils group to another group has a teacher to take more than one way for the activity one, and we have to be flexible with use of the roads. The selection of methods and teaching methods of the processes that the difficult process as the extent of learning and achievement of the aims depends on the right choice of style and manner.

Fourth Axis: Aids and devices used in teaching and learning.

Seen from the Table (5) as follows:

The study sample that means and devices used in the proposed program is appropriate where the proportion ranged from (73.6\%: 100\%) Based on that has been approved at all means and devices used in the proposed program for getting on top of the $70 \%$ of the sample agreement ratio. And get (the board) ratio (100\%), which refers to the appropriateness and adequacy in achieving the aims and easily provided within the school.

These results and higher this ratio refers to the importance of adequacy of means and devices used in the proposed program because it is varied and linked to the objectives of the program suitable for content and help to implement and integrate with, and take into account individual differences, used to strengthen the teaching and learning ways in terms of interest to the student subject you are learning, and diversity experiences help him to learn, and increase its ability to accuracy and observation, and help improve the educational means of communication, and the interpretation of ambiguous concepts, and helps in the formation of positive attitudes towards learning.

Fifth Axis Time frame:

Seen from the Table (6) as follows:

The sample of the study that the time frame for the 
implementation of the proposed program activities are appropriate where the percentage $(97.7 \%)$ and it was based on the approval of the time frame for the implementation of the proposed program activities for having a higher than $70 \%$ of the sample agreement ratio.

The researcher attributes to the fact that the study sample agreement on a suitable time frame for the implementation of the proposed program because it is tied to the content of the program and contribute to achieving the aims, and the implementation of the program for grade on (12) Activity by the activity of each week at two portions.

\section{Sixth Axis: Evaluation methods of program activities}

\section{as follows:}

Seen from the Table (7)

The study sample to evaluate the proposed program activities methods are appropriate where the proportion ranged from (84.3\%: 100\%) Based on that were approved all the proposed program activities calendar methods for getting on top of the $70 \%$ of the sample agreement ratio.
These results are obtaining some of the proposed calendar program activities methods ratio $(100 \%)$, which refers to the importance of this methods and the appropriateness and adequacy of the assessment of the activities of its diversity and its relation to the objectives of the program, and their suitability for evaluating the content, and helps to evaluate students.

The researcher believes that the calendar is one of the basic components of the educational process Through it can recognize the extent to achieve the program objectives and determine the level of students' progress, as well as measure the capacity of students and diagnosis of learning outcomes and treating weaknesses and consolidate the strengths, providing the educational process and to improve the educational process feedback, it is also the process of enhancing the performance of pupils is develop their motivation for further learning, Promoting positive behavior supported and evidenced, and lead at the same time to correct the erroneous behavior where the purpose of the educational 
process is to bring about certain changes in student behavior is achieved through the program, we will be able to make sure to achieve program objectives only through the evaluation process.

\section{Conclusions:}

Through the results of the study, the researcher suggested the following conclusions: -

1. Providing health behavior in sports requires practice, training students on personal health behaviors, health food, preventive health, sports health, mental health, health and skeleton.

2. The researcher's proposal to give the healthy behavior in sports practice for primary school pupils and Attached (3) This shows.

\section{Recommendations:}

In light of the results of the study enables the researcher to ask some of the various recommendations and proposals in the following: -

1. Application of the proposed program is to give health behavior in sports practice for primary school students.

2. Paying attention to the Ministry of Education to give the health behavior at sports practice among primary school pupils and junior high and high school.

3. attention to the training of physical education teachers to raise their culture and health behavior at sports practice.

4. Interests of Physical Education curriculum to include content to give health behavior during sports practice.

\section{References}

1. Aboul Naga Ahmed Izz al-Din: Recent trends in methods of teaching Physical Education, Faculty of Physical Education, Mansoura University, 2000.

2. Ahmed Helmy Alwakeel, Mahmoud Hussein Bashir: curriculum development (its causes, foundations, methods, and gravity, and its obstacles), Dar Al faker Al-araby, Cairo, 2000.

\section{Amani}

Ahmed

Mohammed Abdullah: The Impact of health education program to raise the level of health for pupils of the first stage of primary education,Master Thesis, Faculty of Physical Education, Tanta, 2010.

\section{Amira Khatab Ahmed} speech: the impact of health education program $\mathrm{CNC}$ to improve the health behavior of 
children Foundation (s.o.s) for orphans Gharbia, Master Thesis, Faculty of Physical Education, Tanta, 2008.

5. Bahaa El Din Slama : Health and hygiene education, Dar Al faker Al-araby, Second Edition, $2001 \mathrm{~m}$.

\section{Bahaa El Din Slama:}

Health Aspects of Physical Education, Dar Al faker Alaraby, Second Edition, 1997.

7. Fawzi Taha Ibrahim, Ahmad Rajab Alkelz: contemporary curricula, second edition,, university student library, Mecca, Saudi Arabia, 1999.

\section{Gehan Abdelaziz Jamal} aldin: Effect of education program (healthy - athlete) to reduce the rate of injuries to students of sports experimental schools-Alexandria, Master Thesis, Faculty of Physical Education, Tanta, 2005.

9. Gotay CC1, Shimizu H, Muraoka M, Ishihara Y, Tsuboi K, Ogawa H: Health Attitudes and behaviors: Comparison of the health trends of health and behavior of the Americans of Japanese and European Ancestry, Cancer Research Center of Hawaii, University of Hawaii, 1236 Lauhala St, honolulu, HI
96813, USA 2004 Jun; 10 (2): 153-61

\section{Kamal Abdel-Hamid}

Ismail: A Memoir of Physical Education at the entrance to the first undergraduate students, Faculty of Physical Education in Zagazig, 1999.

\section{Kamal Hossain zaitona :} teaching models and skills, scientific bureau for publication and distribution, Alexandria, 1998.

12. Laila Abdul Aziz
Zahran: scientific and
technical assets to build a
curriculum in physical
education, Dar Zahran
Publishing and Distribution,
Cairo, 2002.

\section{Mahmoud Ramadan}

Hassan: Designing evaluate tag to sport school health for primary school students, Master Thesis, Faculty of Physical Education, Tanta University, 2005.

\section{Makarem}

Abohrjh

Helmy, Mohamed Saad Zaghloul: Physical Education curriculum, elkatab publishing center, Cairo, 2002.

\section{Mohamed Esmat Abd El-} maksoud: health education and health behavior, Faculty of Physical Education for Boys in 
Alexandria, the second edition.1999.

\section{Mohamed}

Sobhi

Hassanein, Mohamed Anwar El-Kholy: refinement and inservice training programs for workers in physical education and sports and recreation and management of sports and sports medicine and sports media, public relations and sports for all, Dar Al faker Alaraby, Cairo, 2001.

17. Mohammad Elsaid Ali : "Education and teaching aids technology," Dar Al faker Alaraby, Cairo, 2002.

\section{Mohammed Massoud} Ibrahim Sharaf: health trends and their relationship to health behavior in the age (9-12 years), Master Thesis, Faculty of Physical Education for Boys, Alexandria University, 2004.

\section{Nasreen Nadi Abdalgid: a} guide to health education for physical education teachers in primary education stage, Ph.D. thesis, Faculty of Physical Education, Assiut University, 2011.

\section{Nawal Ibrahim Shaltout:}

"Teaching in Physical Education Ways", Part two (faculty for teaching and learning), elashaaa Library, Alexandria, 2003.

21.Salah Abd el-Aziz: Modern Education Dar Almaref, Second Edition, 2003.

22.Sandler, Linda, et al., Linking school and health services An Arizona state university, Tempe Marris an inst for public 1995.

23. Shingo N, Tokeo M: the education experiments of school health promotion for the youth in Japan analysis of the (sport test) over the past 34 years, Health prompt international, Jun: 17 (2) P 147-160, Nippon sport science university Tokyo - Japan (2004). 